\title{
Investigating the Relevance of Meese-Rogoff Conclusion in Recent Models of Exchange-Rate Determination
}

\author{
FARAYIBI, Adesoji Oladapo * \\ Centre for Allied Research and Economic Development, Ibadan, Nigeria \\ OWURU, Joel Ede. \\ Department of Economics, University of Ibadan, Nigeria
}

\begin{abstract}
This paper examines the Messe and Rogoff claim of the superiority of random-walk model in the determination of exchange rate in the light of more recent models and empirical results. Random walk model is the traditional model of exchange rate determination while the recent models include the purchasing power parity (PPP), the monetary model and portfolio model. Empirical evidence against the dominance of random-walk in forecasting the behaviours of exchange rate seems to be large or rather inconclusive, since the main thrust of some of the findings is that Messe and Roggoff used out-of-sample test with shorter time horizon which does not have a good econometric justification. Although it cannot be absolutely concluded that economic models are useless in the determination of exchange rate, the relevance of a model in the determination of exchange rate depends on the combination of different factors which vary with time and place.
\end{abstract}

Keywords: Random walk, Exchange-Rate Determination Models, Meese and Rogoff Puzzle.

\section{INTRODUCTION}

In this present era of globalization, there have been increasing trends in cross border flows of goods and services as well as labour and capital mobility. Since these international transactions involve exchange of one currency for another, the issue of exchange rate and its determinants is paramount in the international economic literature. Over four decades now, research related to exchange rate determination and management still remain on the increase, specifically because, apart from the fact that exchange rate refer to relative price which connects domestic and world markets for goods and assets, it also signals the competitiveness of a country with the rest of the world.

Interestingly too, as exchange rate serves as an anchor that supports sustainable internal and external macroeconomic balances of all economies of the world over time, general concessions are far from reach regarding what determines the equilibrium exchange rate between one country's currency and that of its trading or bilateral partner. Indeed, the degree of exchange rate maladjustment or misalignment which is characterized with volatilities remains one of the most challenging empirical problems in open-economy macroeconomics (Williamson 1994 cited by Aliyu 2008). As a result of this inconclusive empirical evidence on the relevance of the basic macroeconomic fundamentals in the determination of exchange rate, there exist various theoretical models and theories purported to explain the interplay of forces that account for varied exchange rate equilibrium.

Chief among these models that are vastly researched by various empirical writers include Purchasing Power Parity (PPP hereafter), the monetary models and the Portfolio balance model.1One of the common concerns in these models is that is foreign exchange market stable or efficient? How do we empirically account for or ascertain the existence of foreign exchange market efficiency and for a consistent predictability of the dynamics or growth paths of exchange rate over time? The objective of this paper is to investigate the validity of Messe and Rogoff, (1983) claim of the superiority of random-walk model in the determination of exchange rate in the light of more recent models and empirical results.

The rest of the paper is organized in this way; section two is the brief examination of the recent models of exchange-rate determination, section three is the empirical reviews while the last chapter is the conclusion.

\section{RECENT MODELS OF EXCHANGE RATE DETERMINATION}

This section discusses some of the recent models of exchange rate determination. Random walk model is the traditional model of exchange rate determination while the recent models include the purchasing power parity (PPP), the monetary model and portfolio model. It is necessary to briefly examine these models in terms of their preoccupation, empirical evidences and possible drawbacks in each of the models.

\footnotetext{
${ }^{1}$ See Gandolfo, (2002) and School of Management course material on International Finance and Globalization, edition 1 (2009) of the University of Leicester for such comment.
} 


\section{The Purchasing Power Parity Model (PPPM)}

From the time past, PPP model is generally seen as the beginning or the starting point of any exchange rate theory. PPP is also called inflation theory of exchange rates (Toshiki and Zhijun Zhao, 2006). PPP can be traced back or is generally attributed to Gustav Cassell's writing in the 1920s, although its intellectual origin dates back to the writings of David Ricardo, a British economist of the nineteenth-century. The basic theory underlying PPP model is that arbitrage forces will lead to the equalization of goods prices internationally once the price of goods are measured in the same currency. As such, the theory represents the "law of one price" (Pilbeam, 2006).

Algebraically, let $P_{i}$ and $P_{i}^{*}$ represents the respective price level of goods $i$ in the home and foreign currency. Also, by denoting the nominal exchange rate that expresses the price in foreign currency in terms of the domestic currency as " $S$ ", and according to the law of one price, the price of one good should be equal at home and abroad, say, $P_{i}=S P^{*}$. By assumption, if the prices of each good are equalized between the two countries and if the goods baskets and their weights in the two countries are the same, then, absolute PPP holds as:

$$
P_{i}=S P^{*}
$$

Absolute PPP theory was first presented to deal with the price relationship of goods with the value of different currencies. The theory requires very strong preconditions. Generally, Absolute PPP holds in an integrated, competitive product market with the implicit assumption of a risk-neutral world, in which the goods can be traded freely without transportation costs, tariffs, export quotas, among other assumptions. ${ }^{1}$ Based on these assumptions, Absolute PPP is generally viewed as a condition of goods market partial equilibrium as there are possibilities of failure of the model because it is practically difficult to integrate both the home and foreign market into a single market.

Relative PPP model is considered to be better than the absolute PPP. Here, Relative PPP describes the relationship of prices with the exchange rate in different economies. We derive relative PPP by assuming that a commodity's home price at time t is $P_{i}$ and the transport cost is $k P_{t}$ where $k$ is constant, the foreign price of the commodity is equal to the price of foreign currency multiplied by the exchange rate $(1+k) P_{t}$ in terms of home currency, that is

$$
(1+\mathrm{k}) \mathrm{P}_{\mathrm{t}}=\mathrm{S}_{t} P_{t}
$$

Using a differential operation on the variables in equation 2, we have the relative PPP expressed as:

$$
\frac{\Delta E_{t}}{E_{t}}=\frac{\Delta P_{t}}{P_{t}}-\frac{\Delta P_{t}^{*}}{P_{t}^{*}}
$$

We can infer from equation 3 that the relative change of the exchange rate equals the difference of the inflation rate between the two economies. Thus, if $\frac{\ln S_{t}}{S_{t}}=s_{t} * \frac{\ln P_{t}}{P_{t}}=p_{t} * \frac{\ln P_{t}^{*}}{P_{t}^{*}}=P_{t}^{*}$ (Equalization of domestic price with foreign price), equation 3 above can be re-specified as:

$$
s_{t}=p_{t}-p_{t}^{*}
$$

From equation 4, if absolute PPP holds, the, the real exchange rate equals one. If relative PPP holds, the real exchange rate should be a constant, but is not necessarily equal to one. If an economy adopts a fixed exchange rate regime, the relative PPP model forecasts that the home prices change at the same speed as foreign prices. Conversely, if the inflation rates in the two economies are the same, according to relative PPP, the exchange rate should be constant.

The foregoing is the theoretical core of PPP model. The proponents and the earlier writers in exchange rate modeling see this theory as an indispensible initial pointer to the long-run changes or dynamics of exchange rate. In this regard, Cassel (1918) as the first to name the theory once argued that without it (PPP), there would be no meaningful way to discuss over-or-under valuation of a currency. Despite the credibility of this model, there is no doubt that Absolute PPP will not hold as the model is built on the assumption of a perfect market setting, because if transport costs, tariffs and trade barriers are not assumed constant, the equilibrium condition

\footnotetext{
${ }^{1}$ See Toshiki and Zhijun Zhao, (2006) and Pilbeam, (2006).
} 
will not hold. This is similar, for instance to the position of Gandolfo, (2002). This author empirically asserts that the basic PPP models results, both in its absolute and relative version fail or at best mixed due to the inherent problem of the wrong assumption of the law of one price which seem to neglect different countries' specific effects that will not allow the assumption of free capital or resource mobility at the international level to operate.

In terms of empirical verification of the validly of this model, Chou and Shih (1998) tested PPP model for the Peoples' Republic of China and found that the renminbi (China currency) was overvalued after the economic reform was launched in 1979, but that PPP holds in the long run. Using the ADF-test and EngleGranger unit root test and integration test, Hu Yuancheng (2003) concluded as quoted Toshiki and Zhijun Zhao, (2006) that the real exchange rate of the renminbi was not stationary, and thus that at least in the short run, PPP does not hold. Pongsak Hoontrakul, (1999) notes further that though controversies over PPP remain, it seems that only relative PPP can hold in the long run (This may explain why PPP was thought by some to be a long-run equilibrium condition instead of short-run equilibrium.

Still on empirical evidence on PPP, Pilbeam, (2006) in his empirical multivariate Time-series econometric modeling of PPP shows that his results are very much in line with those presented by Frenkel (1981), which shows that PPP performs better for countries that are geographically close to one another and where trade linkages are high. Pilbeam notes further that the biggest divergences in his estimation between the actual and the PPP exchange rates are between the pound, deutschmark and yen against dollar, while the lira and French franc rates against the deutschmark are quite accurately tracked by PPP.

Based on his findings, he submits that "not only are France, Italy and Germany are in close proximity to one another thereby minimizing the trade cost, but there are also members of the European Union so that there exist no tariff impediments to restrict trade among them". We therefore conclude that the empirical results of exchange rate determination from PPP model are at best mixed.

\section{The Monetary Model of Exchange Rate Determination}

Monetary theory or model approach to exchange rate determination is one of the modern theories of exchange rate determination. Partly because the PPP discussed above is far from being a satisfactory explanation of observed exchange behavior and for the fact that PPP focuses much on goods arbitrage that capital movement in the international market, it is therefore essential to examine the assets based model of exchange rate, hence the emergence of Monetary and portfolio approaches to exchange rate determination. Following the Second World War and breakdown of the Bretton Woods, the place of monetary economic fundamentals in the determination of exchange rate is at the fore of any reasonable modeling approaches to exchange dynamics at least in the present decade. As developed by Milton Friedman and others at the University of Chicago from the 1950s on and since the mid-1960s, as Mark Taylor suggested, monetary model of exchange rate appears to have become absorbed, with varying degrees of strictness, into the way many economists think about international macroeconomics and finance (School of management, 2009).

Moosa, (2008), deliberated on the neoclassical approach to exchange rate determination as represented by the flexible price monetary model, which is derived from the domestic and foreign demand for money functions. This Author tried to estimate the validity of monetary model of exchange rate determination by specifying the following model:

$$
\mathrm{Md}_{\mathrm{t}}^{*}-\mathrm{P}_{\mathrm{t}}^{*}=\mathrm{aY}_{\mathrm{t}}^{*}-\mathrm{bI}_{\mathrm{t}}^{*}
$$

Where

$\mathrm{Md}=$ logarithm of the demand for money,

$\mathrm{P}=$ logarithm of the price level,

$\mathrm{Y}=$ logarithm of income (output),

$\mathrm{I}=$ interest rate, and

$\mathrm{t}=$ the time span under consideration

An asterisk denotes the corresponding foreign variable, $a$ and $b$ are

Positive constants representing the income elasticity and the interest

Semi-elasticity of the demand for money, respectively

Moosa, demonstrate further that equation 5 can be summed as:

$$
\mathrm{S}_{\mathrm{t}}=P_{t}-P_{t}^{*}
$$

Where:

$\mathrm{S}=$ logarithm of the spot exchange rate which is measured in direct quotation as the domestic currency price of one unit of the foreign currency

$P_{t}$ is the domestic price level and $P_{t}^{*}$ is the foreign price level. Further attempt to linearize the monetary 
model for the purpose of estimation, Moosa, (2008) specified the models below:

$$
\mathrm{S}_{\mathrm{t}}=0+\alpha_{1}\left(\mathrm{M}_{\mathrm{t}}-\mathrm{M}_{\mathrm{t}}^{*}\right)+\alpha_{2}\left(\mathrm{Y}_{\mathrm{t}}-\mathrm{Y}_{\mathrm{t}}^{*}\right)+\alpha_{3}\left(\mathrm{I}_{\mathrm{t}}-\mathrm{I}_{\mathrm{t}}^{*}\right)+\mathrm{t}
$$

Where:

$\mathrm{M}$ and $\mathrm{Y}=$ Domestic Money Supply and domestic level of Income.

$\mathrm{M}^{*}$ and $\mathrm{Y}^{*}=$ Foreign Money Supply and Foreign level of income

The money supply in the model is exogenously determined. It is theoretically expected by the author that $\propto_{1>0,} \propto_{2<0 \text {, and }} \propto_{3}>0$.

His empirical result shows that the effects of interest rates on output are more pronounced when they are combined with the other variables. Thus, the monetary transmission mechanism in international finance is in operation. (Moosa, 2008). The author notes empirically that monetary model is desirable as it is also cleared that PPP is necessary, but not a sufficient condition for the determination of exchange rate.

\section{Portfolio Model of exchange rate determination}

This method is based on a model of portfolio choice between domestic and foreign assets. Basically, in this model, asset holders examine the composition of their portfolio, i.e. the share of domestic and foreign bonds on the basics of consideration of returns and risks. In an attempt to incorporate balance effects into the monetary model equations of exchange rate determination, Jeffrey Frankel (1983 and 1984) expanded the basic derivation of monetary synthesis. ${ }^{1}$ Basically, the portfolio balance model of exchange rate determination allows for the inculcation of changes in perceived risk or risk aversion in determining exchange rate.

For example, an increase in the perceived riskiness of foreign bonds compared to domestic bonds can lead to both a fall in the domestic interest rate and an appreciation of the domestic currency as private agents rebalance their portfolio. Also in the portfolio model, a surplus in the current account implies an accumulation of foreign assets and an increase in domestic wealth. One of the significant policy implication of Portfolio balance model of exchange rate determination as stress by Pilbeam, (2006) is that it helps to ascertain the role that fiscal policy plays in the determination of exchange rate. To him, as bond-based fiscal expansion policy exist, it will ambiguously lead to two effects: While a higher proportion of domestic bonds in an agents' portfolio will lead to an increase in the demand for foreign bonds, the higher domestic interest rate on the other hand will lead to a fall in the demand for foreign bonds.

Overall, residents of a particular economy will be willing to hold (demand) for a higher amount of foreign bonds only if the domestic price that they have to pay for these bonds (exchange rate) is lower.

\section{REVIEWS OF EMPIRICAL STUDIES}

In empirical literature of exchange rate determination, there exist what is known as Meese and Rogoff's Puzzle which relates to weak relationship between nominal exchange rates and market fundamentals (Nahid, 2007). This

Puzzle is also sometimes referred to as the exchange rate disconnect puzzle (Obstfeld and Rogoff, 2000 cited by Nahid, 2007). This puzzle result from the main fact that theoretical models of exchange rate determination which have their derivations or basis from macroeconomic fundamentals fail to empirically outperformed Meese and Rogoff's random-walk model of 1983 in predicting the behavior of exchange rate. In Nahid's word, "Meese and Rogoff's findings are quite striking since a random walk model is not embedded within any economic wisdom or theory. The goals of research on exchange rate predictability over the past two decades have been to uncover the reasons which explain the Meese-Rogoff puzzle and to provide evidence which rejects the random walk forecast model".

The specific empirics of Meese and Rogoff, (1983) are on the determination of the behavior of the exchange rate among three major currencies in relation to Dollar (i.e. dollar/mark, dollar/pound, and dollar/yen). They did that by applying Univariate time series model, an unconstrained vector autoregression, and structural models to test for exchange rate predictability. After rigorous test of the models, they came into conclusion that random-walk model is superior to all competing structural models based on out-of-sample predictability power. Various empirical studies are in support of Meese and Rogoff' claim, while other writers disagree with them.

Vast empirical studies that support or corroborate with Meese and Rogoff's work on the superiority of random-walk model in exchange rate determination and prediction exist. For instance, Cheung et al. (2002) assess various exchange rate models' performance at different level of forecast horizons and still found that none of fundamental models of exchange rate determination consistently outperforms a random walk model. Also, Nahid, (2007) cited Campbell and Clarida (2003), who empirically show that little explanatory power is found in the monetary or portfolio-balance models of exchange rate determination. Since the coefficient of the determination of the models show little explanatory power, it is an indication that the random-walk model of

\footnotetext{
${ }^{1}$ See Frankel. (1983) and Pilbeam, (2006) for the basic mathematical derivation of the model.
} 
Meese and Rogoff (1983) still remain superior.

Furthermore, in support of Meese and Rogoff, Mussa (1985) points out that the natural logarithm of the spot exchange rate follows a random walk, and that any 'serial correlation' found in the exchange rates by 'insample tests' is likely to be unstable over time. Evans and Lyons (2002) assert, "Macroeconomic models of exchange rates perform poorly at frequencies higher than one year". In the words of Frankel and Rose (1995), this negative result has had a "pessimistic effect on the field of empirical exchange rate modeling in particular and international finance in general."

Similarly, there are findings of various studies that do not support the conclusion of Meese and Rogoff on the failure of various economic structural models of the determinants of exchange rate behavior. For example, Chinn Menzie and Ron Alquist (2006) evaluate the performance of the predictive power of three structural models, namely; sticky price monetary model, uncovered interest parity, and a transformation of net exports and net foreign assets model and find that interest rate parity condition holds better at long horizons unlike the prediction of random-walk model.

Taylor and peel (2000) show that in determining the equilibrium level of exchange rate in the long run, unrestricted monetary model is valid and performs better than the random walk. To them, if a country that have experience monetary shocks, the monetary model of exchange rate will be useful in the long run. Also, Kilian and Taylor (2001) evidently showed, based on their empirical study that the predictability power of the spot dollar exchange rate in OECD countries improves unambiguously as the forecast horizon is lengthened from one quarter to several years. This is unlike the conclusion of Meese and Rogoff which was based on short forecast horizon.

Interestingly, Nahid, (2007) tries to empirically give explanation for the dismal performance of structural models of exchange rate in Meese and Rogoff's work. To him, the problem of structural models' misspecification and short time span was inherent in their models, hence their preference of random-walk model. He therefore submits, after investigating the exchange rate behavior among G-7 currencies by extending Meese and Rogoff's data of 1973 to 1981 up to 2005 and inclusion of omitted variables that unambiguously all structural models outperform a random walk, when the data are extended and when the structural model is augmented to capture the stock market channel and other omitted variables. Based on his conclusion, he assert further that these results help in understanding the role of macroeconomic fundamentals in explaining the exchange rate behavior, and that the belief that exchange rates are predictable is a reality.

Further empirical evidence against the conclusion of Meese and Rogoff (1983) still exist. Brooks et al (2001) survey the movements of the euro/dollar and the yen/dollar exchange rates and find that fundamentals like the current account and portfolio flows are the main determinants of exchange rates. Using panel data econometric approach, Mark and Sul, (2001) show evidence of co-integration between exchange rates and macroeconomic fundamentals. Their finding therefore provided evidence which beats random walk forecasts. In the same dimension, Lillie et al (2008) compare forecast performance of some exchange rate exchange rate Models (PPP, Uncovered Interest Rate Parity model, Sticky Price Monetary model and Bayesian Model Averaging technique, and a combination of these models' forecasts.). They presented out-of-sample forecasts of the euro, British pound and Japanese yen against the US dollar in the horizons of one-quarter to eight-quarter ahead. Their empirical results show that depending on the currencies and the forecast horizons, some of these models outperform common benchmarks given by the random-walk model.

Overall, the list of empirical evidence against the dominance of random- walk in forecasting the behaviors of exchange rate seem to be large, if not inconclusive and the main thrust of some of these findings is that out-of-sample test by Meese and Rogoff with shorter time horizon does not have a good econometric justification.

\section{CONCLUSION}

Based on the foregoing disagreement on the superiority of random work mode in out-of-sample test relative to other structural models that are based on economic fundamentals, the position maintained by Taylor and peel, (2000) that random-walk model is weak in econometric technique(s) used in the generation of out-of-sample forecast seem to be relevant. Although, Meese and Rogoff (1983) were right as they maintains that out-ofsample fit is an important criterion to consider when evaluating empirical exchange rate models because insample test (ex-ante test) only fit the data well, but they are incapable in implementing a procedure that is able to account for the frequent shift occurring in the weight that each fundamentals has in deriving exchange rate dynamics.

To fall at the middle line between the extremists on the superiority of random walk model and those in support of the superiority of other economic fundamental models, I agreed with the position of maintains by Rossi, (2005) on the need for synergy between random-walk model and macroeconomic models. In this regard, Rossi (2005) compared monetary model of nominal exchange rate with the random walk in the presence of parameter instability, and concluded that macroeconomic models cannot be assumed insignificant when 
compared with the random walk model and that it cannot also be said that economic models describe exchange rate perfectly. He however discovered that both work together such that economic models can serve to improve predictions made by random models.

The validity of the findings of Messe and Rogoff $(1983,1988)$ that random walk models are a better determinant or forecast of exchange rate as against other economic model vary basically on the basis of the stability of parameters used, the period in focus, model specification and variables involved. However, it cannot be absolutely concluded that economic models are useless in the determination of exchange rate. The relevance of a model in the determination of exchange rate depends on the combination of different factors which vary with time and place.

\section{REFERENCES}

Aliyu S.U.R. (2007b). Import-Export Demand Functions and Balance of Payments Stability in Nigeria: A Cointegration and Error Correction Modeling. MPRA Paper No. 10396

Alquist, R. and Chinn, M. D. (2002). The Euro and the Productivity Puzzle: An Alternative Interpretation. Mimeo.

Brooks, R., Kumar, E. M. \& Slok, T. (2001). Exchange rates and capital Flows. IMF, Research Department, Working Paper 01/190.

Cassel, G., (1918). Abnormal Deviations in International Exchanges. Economic Journal, Vol. 28, pp. $413-415$.

Cheung, Y. W., Chinn, M. D. and Garcia, P. A. (2003). Empirical Exchange Rate Models of the Nineties: Are any Fit to Survive? Working Paper No.551, University of California, Santa Cruz

Cheung, Y. W., Chinn, M.D. \& Pascal, A.G. (2002). Empirical exchange rate models of the nineties: Are any fit to survive?" Unpublished manuscript University of California, Santa Cruz, CA, and University of Munich, Munich Germany.

Clarida, R. H. and Campbel, (2003) The Out-of-Sample Success of Term Structure Models as Exchange Rate Predictors: A Step Beyond. Journal of International Economics, 60, pp. 61-83.

Frankel, J. A. and Rose, A. K. (1983) Empirical Research on Nominal Exchange Rates, in Handbook of International Economics, Vol. III (Eds) G. Grossman and K. Rogoff, Elsevier-North Holland, Amsterdam, pp. 1689-1729.

Frenkel, J. A. (1981) The Collapse of Purchasing Power Parities during the 1970s. European Economic Review, 1981, 6(1), pp. 145-165.

Frenkel, J. A. (1981b). Flexible Exchange Rates, Prices, and the Role of News: Lessons from the 1970's. Journal of Political Economy Vol. 89, 705.

Flood R. and A. Rose (1985). Fixing Exchange Rates: A Virtual Quest for Fundamentals. Journal of Monetary Economics, 36(1), pp. 3-37.

Killian, L., \& Taylor, M. P. 2001. "Why is it so difficult to beat the random walk forecast of exchange rates?" The European Central Bank, Working Paper 88, Frankfurt, Germany.

Meese, R. A. and Rogoff, K. (1983) Empirical exchange rate models of the seventies: do they fit out of sample? Journal of International Economics 14(1/2): pp. 3-24

Moosa, I.A. (2008) Neoclassical versus Post Keynesian Models of Exchange Rate Determination: A Comparison based on Nonnested Model Selection Tests and Predictive Accuracy.

Mussa, Meese and Rogoff, (1985). The Theory of Exchange Rate Determination. National Bureau of Economic Research. University of Chicago, Press.

Pilbeam. K. (2006) International Finance. Palgrave Macmillan Publishers, Third edition.

Obstfeld, M., Rogoff, K., 2000. The six major puzzles in international macroeconomics: is there a common cause? In: NBER Macroeconomics Annual, vol. 15.

Rossi, B. (2005) Are Exchange Rates Really Random Walks? Some Evidence Robust to Parameter Instability School of Management (2009). Course material on International Finance and Globalization, edition 1 (2009) of the University of Leicester.

Shiu-Sheng, C. (2004) Real Exchange Rate Fluctuations and Monetary Shocks: A Revisit. International Journal Of Finance And Economics Vol. 9, pp. 25-32.

Taylor, M. P. and Peel, D. (2000) Nonlinear Adjustment, Long-Run Equilibrium and Exchange Rate Fundamentals. Journal of International Money and Finance, vol. 19, pp. 33-53.

Toshiki and Zhijun Zhao, (2006)The Renminbi Exchange Rate Revaluation: Theory, Practice and Lessons from Japan. Asian Development Bank Institute. Knowledge Management Unit.

$\mathrm{Hu}$ Yuancheng (2003) Empirical Exchange Rate Models of the Nineties: Are Any Fit to Survive?

Mark, N. C., \& Sul, D. 2001. "Nominal exchange rates and monetary fundamentals evidence from a small postBretton Woods panel", Journal of International Economics, Vol. 53, pp. 29-52.

Nahid, K. Anaraki (2007) Meese and Rogoff's Puzzle Revisited International Review of Business Research Papers Vol.3 No.2 June 2007, Pp. 278- 304 